\title{
BERMAZHAB DAN FANATIK MAZHAB: SATU SOROTAN DALAM KERANGKA AMALAN BERMAZHAB SYAFI'I MASYARAKAT MELAYU
}

\author{
Oleh: \\ Luqman Haji Abdullah* \\ Nima Jihatea ${ }^{* *}$
}

\begin{abstract}
Generally, the Malay society in Malaysia has been practicing Shafi ite mazhab since hundreds of years whether on taqlid or knowledge basis. This can be supported by the historical account of their daily practice, fatwas, laws and the curriculum at schools which show that the Shafitite mazhab has been dominating over the others. This article attempt to analyze this phenomenon based on two premises in the subject of Usul al-Fiqh, namely, al-tamadhub which is regarded as a necessity for certain level of people and madhabic fanatisme which is considered not in line with the Islamic principles. It is vital to determine that the prevalent Malay practice of madhab is in line with the concept of al tamadhub and not madhabic fanatisme.
\end{abstract}

* Pensyarah Kanan, Jabatan Fiqh \& Usul, Akademi Pengajian Islam, Universiti Malaya, Kuala Lumpur.

** Pensyarah, Jabatan Ilmu Wahyu \& Sains Kemanusian, Pusat Pengajian Asasi, Universiti Islam Antarabangsa Malaysia,Petaling Jaya. 


\section{PENDAHULUAN}

Amalan bermazhab Syafi'i di Malaysia adalah suatu penerusan tradisi yang telah lama kerana faktor sejarahnya yang tersendiri. Perkembangan dan pertapakan mazhab Syafi'i di negara ini adalah seiring dengan perkembangan Islam di rantau ini hasil usaha pendakwah-pendakwah yang datang ke sini. Sejarah ini merupakan sejarah yang perlu dibanggakan kerana ia telah menukar rantau ini kepada rantau Islam. Telah ditakdirkan mazhab yang datang ke nusantara ini ialah mazhab Syafi'i dan bukannya mazhab Hanafi, Maliki atau Hanbali. Berdasarkan faktor sejarah ini sampai sekarang negara Malaysia masih tetap utuh dengan mazhab Syafi'i dan tidak diatasi oleh mazhab-mazhab lain.

Dengan arus idealisme tajdid fiqh yang berlaku di seluruh dunia Islam, walaupun masih di peringkat minoriti, atau laungan kembali kepada Quran dan Sunnah sebagaimana generasi salaf, walaupun beberapa aspek teknikal boleh dipertikaikan, kedudukan bermazhab Syafi'i dalam bentuk pengamalan di Malaysia samada oleh individu atau pemerintah sekarang ini dilihat sudah tidak syar' $\bar{i}$ kerana dianggap bertaklid buta yang dikeji dan fanatik kepada mazhab Syafi'i. Hasilnya lahir golongan yang menolak mazhab (lā madhhabiyyah) yang kesannya ialah meruntuhkan kazanah fiqh yang telah terbina sekian lama bahkan meruntuhkan manhaj hukum yang telah dibina oleh fuqaha terdahulu. Dari sudut yang lain pula ada usaha untuk mempertahankan tradisi yang ada dengan membawa perubahan yang perlu dalam kerangka prinsip bermazhab atau pengekalan manhaj Syafi'i tetapi dengan interpretasi semasa dengan mengambil kira perubahan budaya dan uruf.

Artikel ini bertujuan mengkaji dan menilai realiti di antara bermazhab dan fanatik mazhab dalam konteks masyarakat Islam di Malaysia. Apakah kedudukan masyarakat Melayu yang bermazhab Syafi'i boleh disifatkan sebagai suatu keadaan yang diharuskan dan dipertahankan atau ia boleh disifatkan sebagai masyarakat yang fanatik mazhab yang dicela yang mesti diislahkan. 


\section{KONSEP BERMAZHAB}

Huraian konsep bermazhab dalam artikel ini adalah merupakan huraian konsep taqlid dalam pengajian Ușūl al-Fiqh. Istilah bermazhab diguna pakai kerana ia lebih mudah untuk difahami dalam konteks amalan bermazhab di negara kita. Setiap individu atau negara dikatakan bermazhab dengan sesuatu mazhab tertentu kerana ia menerima pakai atau bertaqlid kepada mazhab tersebut. Oleh itu bermazhab adalah membawa maksud bertaqlid kepada mazhab yang dipegangi.

Mazhab adalah berasal daripada perkataan Arab yang bermaksud: "cabang ajaran Islam yang diikuti oleh umat Islam, iaitu seperti: mazhab Hanafi, Maliki, Syafi'i dan Hanbali. Manakala perkataan bermazhab (madhhabiyyah) sebagaimana yang ditakrifkan oleh Sai'īd Ramaḍān al-Būți membawa maksud seseorang awam atau orang yang tidak sampai ke tahap mujtahid berpegang atau mengikut (taqlid) mana-mana aliran Imam mujtahid samada dia berpegang dengan seorang mujtahid sahaja atau berpindah-pindah antara satu mujtahid ke mujtahid yang lain dalam ikutannya itu. ${ }^{2}$ Takrif ini adalah hampir sama dengan takrif taqlid dalam pengajian Usul al-Fiqh iaitu mengambil pandangan orang lain tanpa mengetahui dalil. ${ }^{3}$

Terdapat polemik yang popular dalam pengajian Usul al-Fiqh tentang kedudukan bertaqlid ${ }^{4}$ yang boleh dikategorikan kepada tiga pandangan: ${ }^{5}$

Kamus Dewan (2002), ed. 3. Kuala Lumpur: Dewan Bahasa dan Pustaka, h. 871.

2 Sai ìd Ramaḍān al-Būṭi (1985), al Lā Madhhabìyyah. Damsyiq: Dār al-Fārabì, h. 14.

3 Wahbah al-Zuhaylì (1996), Ușūl al-Fiqh al-Islāmī, j. 2. Damsyiq: Dār al-Fikr, h. 1120.

4 Yang dimaksudkan dengan taqlid di sini ialah taqlid dalam masalah furu' fiqh dan bukannya taqlid dalam masalah usul atau akidah kerana taqlid dalam dua masalah ini adalah tidak dibolehkan sama sekali.

5 Wahbah al-Zuhayli (1996), ibid., hh. 1126-1129; Nadiyah Syarīf al'Umrì (2004), Al-Ijtihād wa al-Taqlìd fí al-Islām. Beirut: Mua'ssasah al-Risālah, hh. 271-273. 
1. Tidak harus bertaqlid sama sekali. Wajib ke atas setiap mukallaf berijtihad sendiri mengenai urusan agamanya dan beramal berasaskan ijtihadnya. Ini adalah pandangan golongan al-Zahiri dan al-Mu'tazilah.

2. Bertaqlid adalah wajib ke atas semua mukallaf selepas zaman imam-imam mujtahidin. Ini adalah pandangan Hasyawiyyah.

3. Ijtihad adalah tidak dilarang manakala taqlid adalah haram ke atas para mujtahid. Manakala orang awam yang tidak berkeahlian berijtihad sekalipun seorang yang alim adalah wajib bertaqlid. Pandangan ini merupakan pandangan jumhur ulama dan inilah pandangan yang ditarjihkan oleh kebanyakan ulama semasa.

Penulis sangat bersetuju dengan pandangan yang ketiga di atas kerana inilah pandangan yang realistik. Bagaimana mungkin untuk meletakkan kewajipan berijtihad ke atas orang yang tidak mempunyai alat yang cukup untuk berijtihad. Syariat Islam yang mudah ini tidak mengenakan taklif ke atas orang yang tidak mampu untuk melaksanakannya. Demi kemudahan orang awam melaksanakan tuntutan syarak, harus baginya bertaqlid manamana imam mujtahid yang diyakininya. Rentetan dari pandangan yang ketiga di atas para ulama telah membahagikan taqlid kepada dua iaitu:

1. Taqlid yang dipuji iaitu taqlid seorang yang tidak berkelayakan untuk berijtihad lalu dia bertaqlid kepada mujtahid

2. Taqlid yang dicela iaitu taqlid dalam perkara yang berlawanan dengan syara' seperti bertaqlid buta kepada pemimpin atau orang tua, bertaqlid kepada seorang yang tidak diketahui samada dia berkelayakan untuk ditaqlidkan dan bertaqlid setelah ternyata dalil dan hujah baginya bahawa orang yang ditaqlidkan itu adalah silap.

Menurut Wahbah al-Zuhayli, taqlid dalam kategori kedua di atas merupakan maksud larangan taqlid sebagaimana yang ada dalam teks-teks fuqaha yang mencela taqlid seperti larangan para imam mujtahid dari bertaqlid kepada mereka tanpa hujah.

Bertaqlid bagi orang awam bukanlah suatu yang di luar prinsip syarak tetapi suatu keperluan baginya yang selaras dengan kehendak syarak. Sebagai seorang Muslim, tidak semuanya 
mampu memahami tentang agama. Malah ia perlu berpandukan kepada para ulama untuk memahami nas-nas syara'. Justeru itulah manusia diwajibkan bermazhab sebagai beramal dengan ayat Quran yang menyuruh umat Islam bertanya kepada ahl al-dhikr (orang yang tahu) sekiranya mereka tidak mengetahui. Muhammad Sai 'ìd Ramaḍān al-Būțī menegaskan wajib bagi orang yang lemah (tidak dapat) berijtihad untuk bertaqlid tetapi bukan secara fanatik, yang mana harus baginya untuk beriltizam atau tidak. ${ }^{6}$

Keharusan bertaqlid sebagaimana yang dihurai di atas mestilah dalam kerangka yang telah disepakati oleh para ulama sebagaimana yang dihurai oleh al-Būți iaitu: ${ }^{7}$

1. Dalam persoalan taqlid tidak ada nas syara' yang menyuruh supaya berpegang kepada mazhab secara berterusan sebagaimana juga tidak ada nas syara' yang melarang berpindah mazhab. Dalam konteks ini al-Būți menegaskan ketiadaan nas yang menyuruh beriltizam dengan mazhab tertentu bukan pula bererti haram beriltizam dengan mazhab kerana tidak wajib bukannya bermaksud haram.

2. Apabila ternyata bagi seorang muqallid dalil-dalil syara' dan ușūl ijtihad wajib baginya melepaskan diri dari pendapat imam mazhabnya. Ini yang dinamakan mujtahid mazhab. Di sini al-Būṭi menegaskan bahawa ia bukan bermaksud menyuruh orang jahil supaya tidak bertaqlid dan berpegang terus kepada al-Quran dan Sunnah.

3. Semua para imam mujtahid adalah berada di atas kebenaran iaitu ijtihad mereka itu tidak dianggap salah di sisi Allah. Al-Būṭi menegaskan dari sinilah asasnya bahawa bertaqlid kepada salah satu imam mazhab adalah bertaqlid di atas kebenaran. Tidak harus bagi seseorang yang berpegang kepada satu-satu mazhab untuk menganggap mazhab lain adalah salah.

Inilah prinsip asas bermazhab atau bertaqlid dalam tradisi pengajian fiqh dan usul fiqh. Sebarang pandangan yang di luar dari kerangka ini adalah menyalahi konsep bermazhab dan

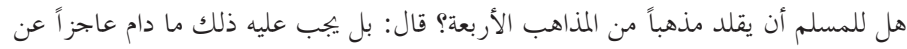

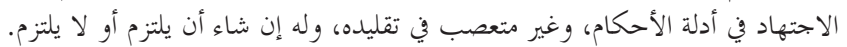

7 Sai ìd Ramaḍān al-Būṭ̂i (1985), op.cit., hh. 37-38. 
bertegas untuk menyalahi konsep ini adalah satu sikap fanatik yang dicela.

Berdasarkan huraian di atas mari kita lihat di mana kedudukan fanatik mazhab. Dalam istilah usul, fanatik dikenali dengan taksub. Perkataan taksub berasal daripada perkataan Arab yang bererti: "tidak menerima kebenaran tentang pandangan dan pendapat orang lain yang berdasarkan dalil-dalil syar'i, disebabkan kecenderungan seseorang kepada aliran tertentu. ${ }^{8}$ Perkataan taksub tidak terdapat dalam kamus Dewan. Apa yang terdapat di dalamnya adalah perkataan "fanatik". Fanatik bererti keterlaluan pada sesuatu pegangan atau pendirian berkaitan dengan agama. ${ }^{9}$ Pengertian yang hampir sama juga terdapat pada perkataan "eksterim". Kamus Dewan mendefinisikan eksterim sebagai keterlaluan dan melampau. Ekstremis pula bererti orang yang sikapnya keterlaluan dan melampau dalam sesuatu hal seperti agama, politik dan sebagainya. ${ }^{10}$

Menggunapakai takrif di atas boleh disimpulkan di sini bahawa amalan bermazhab sebagaimana yang dihurai di atas bukanlah bermaksud fanatik kepada mazhab yang diikut tetapi semata-mata di atas keperluan bagi orang awam yang tidak mempunyai cukup keahlian ilmu untuk berijtihad sendiri. Tuduhan bermazhab sebagai fanatik adalah tuduhan tidak berasas sama sekali berasaskan kepada maksud bermazhab atau bertaqlid sebagaimana yang diterima dalam pengajian Usul Fiqh. Realiti yang ada ialah para imam mujtahid telah meletakkan kaedah dalam berinteraksi dengan nas dan menangani masalah hukum dan usaha mereka ini telah diikut oleh orang yang tidak mampu untuk berijtihad yang telah melahirkan golongan yang berpegang kepada kaedah dan pandangan para mujtahidin tadi yang dipangil muqallid.

\footnotetext{
8 Qāmūs al-Munjid (1994), c. 34, Beirut: Dār al-Masyriq, h. 508.

$9 \quad$ Kamus Dewan, op.cit.., h. 349.

10 Kamus Dewan, ibid., h. 330.
} 


\section{MAZHAB SYAFI'I DAN KERANGKA PENGAMALAN- NYA DI MALAYSIA}

Satu kenyataan yang tidak dapat dinafikan umat Islam di Negara Malaysia secara umumnya adalah bermazhab Syafi'i. Kenyataan ini bukanlah bermaksud untuk menafikan kewujudan amalanamalan mazhab selain Syafi'i di peringkat individu dan institusi tetapi ia merujuk kepada fakta sejarah perkembangan Islam di Malaysia dan dominasi mazhab Syafi'i dalam banyak aspek kehidupan berugama dalam kalangan umat Islam di Malaysia. Walaupun mungkin kebanyakan masyarakat mengamalkan mazhab Syafi'i dalam kehidupan seharian secara warisan sahaja tanpa sebarang ikatan dengan maklumat ilmiah terhadap mazhab yang dianuti ia sebenarnya adalah sebahagian daripada proses pengukuhan mazhab Syafi'i dalam masyarakat Islam di Malaysia. Paling kurang kenyataan bahawa Malaysia bermazhab Syafi' $i$ boleh dipertahankan atas alasan ia telah diinstitusikan dalam bentuk resmi melalui fatwa-fatwa yang dikeluarkan dan enakmen pentabiran agama negeri-negeri yang menggunapakai mazhab Syafi'i secara meluas dengan sedikit pengecualian kepada negeri Perlis. Kedudukan yang resmi ini sudah cukup untuk membuktikan kenyataan di atas. Penerimaan secara resmi oleh sesebuah kerajaan terhadap sesuatu aliran sudah tentu memberi kesan secara langsung dari segi pengamalannya di peringkat rakyat.

\section{Sejarah Perkembangan}

Dari sudut sejarah, perkembangan Islam di Tanah Melayu adalah sebahagiannya bermula dari pendakwah-pendakwah yang datang dari Pasai (Perlak) yang mana Pasai pada ketika itu merupakan pusat pengajian Islam dan juga penyebaran dakwah Islam ke Melaka, Jawa dan Patani. Riwayat Ibn Bațuttah ada mencatatkan penguasaan mazhab Syafi'i ke atas Raja Pasai (Perlak) al-Mālik al-Zāhir (1326-1350M) yang mana sebelum daripada itu ia dikuasai oleh golongan Syiah. Disebut dalam sejarah tokoh yang bertanggungjawab membawa aliran sunni Syafi'i ke rantau ini ialah Syeikh Isma'il Siddiq yang diutus khas dari Mekah oleh Syarif Mekah ke Pasai. Pertapakan mazhab Syafi'i semakin kuat di negeri tersebut semenjak itu dan dari situlah berkembangnya mazhab Syafi'i ke Tanah Melayu selari dengan perkembangan 
Islam. ${ }^{11}$ Ada kajian yang mengatakan penyebaran mazhab Syafi' $i$ oleh Sheikh Isma'il Siddiq adalah suatu usaha yang dirancang demi untuk mengubah fahaman Syiah yang dianuti penduduk Pasai yang pada masa itu berada di bawah pemerintahan kerajaan Mamluk Turki (1252-1517M). ${ }^{12}$

Dalam konteks perkembangan Islam di Tanah Melayu kedatangan mazhab Syafi'i ke Melaka mempunyai kaitan dengan Pasai iaitu ia dibawa oleh Sayyid 'Abd al-Aziz sebagai pendakwah dan beliau mempunyai pertalian dan hubungan dengan Syeikh Isma'il Siddiq. Mereka berdua berasal dari Semenanjung Tanah Arab yang ketika itu merupakan wilayah Islam di bawah pengaruh mazhab Syafi'i. ${ }^{13}$ Dari catatan sejarah ini boleh disimpulkan perkembangan mazhab Syafi‘i di Tanah Melayu adalah bermula dari Pasai yang menyaksikan juga terhapusnya dominasi Syiah di rantau tersebut. Perkembangan ini turut dipacukan juga kemudianya dengan peranan pendakwah Arab yang datang dari Hadramaut yang bermazhab Syafi ‘ ${ }^{1}{ }^{14}$

Fakta sejarah ini juga sebenarnya diakui oleh ahli-ahli sejarah Barat yang menulis mengenai kedatangan Islam ke nusantara yang mana mereka menerima mazhab Syafi'i sebagai mazhab paling dominan dalam pengajian fiqh di nusantara. ${ }^{15}$ Perkembangan mazhab ini bukan sahaja di peringkat amalan seharian tetapi juga

11 Mahayudin Haji Yahya (1998), Islam Di Alam Melayu, Kuala Lumpur: Dewan Bahasa \& Pustaka, hh. 170-171.

12 Mahmud Zuhdi Hj Abdul Majid \& Paizah Hj Ismail (2006), Pengantar Pengajan Syariah. Kuala Lumpur: Al-Baian Corporation, h. 29; Abdul Rahman b. Hj. Abdullah (1989), Islam Dalam Sejarah Asia Tenggara Tradisional. Kuala Lumpur: Penerbit Pena Sdn. Bhd., h. 105; A.H. Hill (1960), "Hikayat Raja-Raja Pasai” dalam JMBRAS, vol. 33, Jun, hh. 58-60.

13 Abdullah Ishak (1992), Islam di Nusantara (khususnya di Tanah Melayu), Kuala Lumpur: Bahagian Hal Ehwal Islam, Jabatan Perdana Menteri, hh. 55-60.

14 Abdul Rahman b. Abdullah (1990), Perkembangan Umat Islam Di Nusantara: Sejarah dan Perkembangannya Sehingga Abad ke-19M. Kuala Lumpur: Dewan Bahasa dan Pustaka, hh. 226-227.

15 John Crawfurd (1877), History of The Indian Archipelago. London: Frank Cass and Co. Ltd., vol. III, p. 77. 
sampai ke peringkat undang-undang. Dari sudut pembuktian sejarah dalam konteks ini boleh dikesan seawal pembentukan Hukum Kanun Melaka di zaman pemerintahan Sultan Muzaffar Shah (1445-1450M) yang mana pada keseluruhannya adalah berasaskan fiqh mazhab Syafi'i dengan tidak menafikan ada unsur percampuran dengan undang-undang adat. ${ }^{16}$ Kanun Melaka ini kemudiannya mempengaruhi pembentukan Undang-undang Johor, Undang-undang Pahang, Undang-undang Sembilan Puluh Sembilan Perak dan Undang-undang Sungai Ujong. ${ }^{17}$ Pengaruh mazhab Syafi'i dalam undang-undang yang dibentuk di zaman kesultanan Melayu Melaka dan seterusnya ke negeri-negeri lain adalah menggambarkan sejauh mana penguasaan mazhab tersebut dalam masyarakat pada masa tersebut dan juga di peringkat pemerintah.

\section{Pengaruh Karya-karya Fiqh Syafi'i di Malaysia}

Pengukuhan mazhab Syafi'i di alam Melayu juga boleh dilihat dengan jelas sekali berdasarkan karya-karya fiqh mazhab Syafi'i yang banyak mempengaruhi pengajian masyarakat Melayu di surau dan madrasah. Antara yang masyhur ialah kitab Minhāj alTạlibìn karangan Imām al-Nawawi yang dikatakan dibawa masuk ke nusantara pada abad ke 13 yang kemudiannya dikembangkan di Melaka secara khususnya selari dengan perkembangan Islam. Selain Minhāj al-Tálibìn, kitab-kitab fiqh Syafi' 'i yang lain seperti Muhadhdhab bagi al-Syirāzi juga turut dijadikan teks pengajian pada zaman awal kemasukan Islam ke Tanah Melayu. ${ }^{18}$ Dalam perkembangan seterusnya kita juga melihat semakin banyak kitabkitab fiqh Syafi'i dibawa masuk dan dipelajari atau dijadikan rujukan sehingga hari ini seperti Tuhfat al-Muhtāj bagi Ibn Hajar, Nihâyat al-Muḥtāj bagi al-Ramli, Mughni al-Muḥtāj dan al-

\footnotetext{
16 Abdul Kadir b. Hj. Muhammad (1996), Sejarah Penulisan Hukum Islam di Malaysia. Kuala Lumpur: Dewan Bahasa dan Pustaka, h. 11; Mahmud Saedon Othman (1996), Institusi Pentadbiran Undangundang \& Kehakiman Islam. Kuala Lumpur: Dewan Bahasa dan Pustaka, hh. 218-219.

17 Mahmud Saedon Othman (1996), ibid.,hh. 222-223.

18 Mahmud Zuhdi Hj Abdul Majid \& Paizah Hj Ismail (2006), op.cit., h. 229.
} 
Iqnā' bagi al-Syarbīni, Fath al-Wahhāb bagi Zakariyā al-Ansārī, al-Ashbāh wa al-Nazā'ir bagi Suyūți, Fath al-Mu'in bagi Zain al-Dìn al-Mālibārì dan lain-lain. Kitab-kitab ini telah menguasai dunia ilmiah di Malaysia sejak sekian lama samada sebagai teks pengajian atau sumber rujukan dalam fatwa dan kodifikasi undang-undang.

Di samping kitab-kitab Arab terdapat juga karya-karya fiqh yang dihasilkan oleh ulama nusantara yang menjadi rujukan dalam masyarakat Melayu. Seawal abad ke 17 Masihi nusantara menyaksikan penghasilan karya-karya fiqh dalam mazhab Syafi' $i$ terutamanya dari Acheh dan Pattani yang kemudiannya tersebar ke Tanah Melayu. Syeikh Abdul Rauf Singkel adalah antara yang terawal menghasilkan kitab fiqh Syafi'i dalam bahasa Indonesia yang bertajuk Mir'at al-Tullāb fì Tashìl Ma'rifah Ahkām alSyar'iyyah lì Màlik al-Wahhāb yang bersumberkan kitab-kitab muktabar mazhab Syafi‘i. Ulama besar dari Kalimantan iaitu Muḥammad Arsyād al-Banjari menulis kitab Sabìl al-Muhtadīn di atas permintaan Sultan Banjar yang juga berasaskan fiqh Syafi ‘ ${ }^{19}{ }^{19}$ Kitab Sirāt al-Mustaqīm tulisan Sheikh Nuruddin al-Rāniri merupakan teks fiqh terawal di Alam Melayu yang banyak memberi sumbangan dalam pengukuhan mazhab Syafi' $i{ }^{20}$ Di samping itu kitab-kitab Syeikh Daud al-Fațțani seperti kitab Fur $\bar{u}^{\prime}$ al-Masā' 'il, Bughyat al-Tullāb, Munyat al-Mușalli, Sullam al-Mubtadì dan lain-lain adalah di antara kitab-kitab yang beredar dalam kalangan masyarakat Melayu dahulu dan sekarang yang sudah tentu begitu kuat menanamkan pengaruh mazhab Syafi'i dalam masyarakat. Kitab-kitab ini bersumberkan kitab-kitab muktabar dalam mazhab

19 Amir Syarifuddin (1995), "Pengaruh mazhab Syafi‘ ‘ Dalam Pengajian Fiqh dan Usul Fiqh di Asia Tenggara", dalam Kertas Kerja Seminar Antarabangsa Pengajian Islam di Asia Tenggara. Brunei: Universiti Brunei Darussalam, 20-23 November 1995, hh. 11-12.

20 Abdul Kadir b. Hj. Muhammad (1996), Sejarah Penulisan Hukum Islam di Malaysia. Kuala Lumpur: Dewan Bahasa dan Pustaka, h. 32; Fadhlullah Jamil (1422H/2001M), "Peranan Ulama Pondok dan Karya-Karya Penulisan Mereka Dalam Membangunkan Islam di Malaysia”, dalam Kertas Kerja Seminar Bahan Rujukan Islam Nusantara, Jabatan Mufti Kerajaan, Jabatan Perdana, Negara Brunei Darussalam, hh. 5-6. 
Syafi'i seperti yang telah disebutkan di atas. Walaupun dari segi kenyataannya kitab-kitab ini banyak beredar di peringkat pondok dan madrasah tetapi pengaruhnya cukup kuat kerana ia sangat dekat dengan masyarakat umum berbanding dengan peringkat lain dalam pengajian.

Selain dari kitab-kitab klasik di atas kitab-kitab baru yang bermazhab Syafi'i juga mendapat tempat dalam masyarakat Melayu sekarang. Antara yang popular pada masa kini ialah kitab fiqh Syafi'i yang merupakan terjemahan kepada kitab al-Fiqh alManhājī 'alā al-Madhhab al-Syafi 'i karangan Muștafā al-Bughā, Mușțafã al-Khin dan Ali al-Syarabji. Kitab ini banyak dijadikan teks untuk kuliah-kuliah awam di masjid-masjid dan surau bahkan di peringkat universiti.

Kitab-kitab fiqh mazhab Syafi'i inilah juga yang menjadi rujukan dalam penyediaan buku-buku pengajian Islam di sekolahsekolah rendah dan menengah kebangsaan di bawah kementerian pelajaran Malaysia dan juga buku-buku KAFA yang mana kurikulumnya adalah berasas kepada mazhab Syafi 'i. Sebenarnya kurikulum pengajian ini yang banyak menyumbang kepada pengukuhan mazhab Syafi'i di Malaysia kerana ia merupakan fiqh peringkat asas kepada seseorang muslim yang melibatkan amalan sehariannya.

\section{Mazhab Syafi'i Dalam Perundangan dan Fatwa}

Kedudukan mazhab Syafi'i di Malaysia diperkukuhkan lagi melalui peruntukan undang-undang melalui enakmen negerinegeri. Mengambil kira sejarah perkembangan mazhab Syafi ‘i di Malaysia pihak berkuasa negeri telah mengambil langkah dengan lebih jelas iaitu menerimapakai mazhab Syafi' $i$ dalam fatwa-fatwa negeri. Sebagai contoh Akta Pentadbiran Undang-undang Islam (Wilayah Persekutuan) 1993 memperuntukkan dalam Seksyen 39:

(1) Dalam mengeluarkan apa-apa fatwa di bawah seksyen 34, atau memperakukan apa-apa pendapat di bawah seksyen 38, mufti hendaklah pada lazimnya mengikut pandanganpandangan diterima (qaul muktamad) mazhab Syafi‘i.

(2) Jika Mufti berpendapat bahawa dgn mengikut qaul muktamad mazhab Syafi'i akan membawa kepada keadaan 
yangg berlawanan dengan kepentingan awam, Mufti bolehlah mengikut qaul muktamad mazhab Hanafi, Maliki dan Hanbali.

(3) Jika Mufti berpendapat bahawa tiada satu pun qaul muktamad daripada empat mazhab itu boleh diikuti tanpa membawa kepada keadaan yang berlawanan dengan kepentingan awam, Mufti bolehlah menyelesaikan persoalan itu mengikut hematnya sendiri tanpa terikat dengan qaul muktamad daripada mana-mana mazhab yang empat itu.

Jelas dari peruntukan di atas keutamaan mazhab Syafi'i dalam fatwa berbanding dengan mazhab lain. Satu-satunya perkara yang diambil kira untuk menerimapakai mazhab selain Syafi'i ialah kepentingan awam. Ini adalah satu bentuk siyasah syariyyah daripada pihak pemerintah demi untuk menjaga kemaslahatan keharmonian hidup beragama di Negara kita yang telah sebati dengan mazhab Syafi'i dengan pada masa yang sama memberi ruang kepada mazhab lain dalam fatwa jika ada kepentingan awam. Kaedah penyeragaman ini sangat perlu diambil perhatian oleh semua pihak agar keharmonian hidup masyarakat Islam tidak tergugat dengan pendapat-pendapat yang lain dari mazhab Syafi' $i$ yang tidak perlu diketengahkan untuk masyarakat awam.

Dalam perkembangan yang sama Jawatankuasa Fatwa Wilayah Persekutuan telah memutuskan beberapa ketetapan seperti berikut: ${ }^{21}$

(1) Semua fatwa yang diputuskan mestilah berdasarkan kepada qawl yang muktabar dalam mazhab Syafi'i. Jika hendak beramal dengan qawl dari mazhab lain maka perlu mendapat restu dariada Yang Di Pertuan Agong

(2) Umat Islam tidak dipaksa beramal dengan mazhab Syafi' $i$ bahkan boleh beramal dengan mana-mana mazhab lain yang disukai dengan syarat mereka tidak boleh menyalahkan orang-orang yang beramal dengan mazhab Syafi ${ }^{\circ} i$.

${ }^{21}$ Ahmad Hidayat Buang (2004), "Analisis Fatwa-fatwa Syariah di Malaysia", dalam Fatwa Di Malaysia Kuala Lumpur: Jabatan Syariah dan Undang-undang Universiti Malaya, h. 167. 
(3) Mazhab-mazhab lain tidak boleh diajar atau disyarah secara terbuka di khalayak ramai namun boleh diajar di majlismajlis pelajaran

(4) Menjadi satu kesalahan jika mengajar mazhab lain selain daripada mazhab Syafi'i secara terbuka

(5) Jika fatwa telah dikeluarkan berasaskan kepada mazhab Syafi'i, maka tiada sesiapa pun boleh membantahnya dengan menggunakan hujah daripada mazhab yang lain

Selain daripada itu Jakim telah menerima pakai cadangan Majlis Kebangsaan Bagi Hal Ehwal Islam agar penyebaran fahamanfahaman selain mazhab Syafi'i hendaklah dikawal bagi tujuan membendung fahaman yang boleh mengelirukan masyarakat yang tidak terdedah dengan perbezaan mazhab-mazhab. Cadangan ini telah diperkenan oleh Mesyuarat Majlis Raja-raja ke 133 (khas) pada 3 disember $1984 .{ }^{22}$

Apa yang jelas dari peraturan ini ialah untuk menjaga orang awam dari terdedah kepada kekeliruan aliran mazhab yang berbagai. Dengan kedudukan mazhab Syafi'i yang telah sebati dalam khidupan mereka tentunya akan timbul kekeliruan jika mazhab lain turut didedahkan kepada awam.

\section{BERMAZHAB BUKAN FANATIK MAZHAB}

Kedudukan mazhab Syafi'i di Negara ini sebagaimana yang dibentangkan di atas adalah hasil perkembangannya dalam sejarah yang panjang. Perkembangan mazhab menyebabkan bertapaknya mazhab Syafi‘i dan akhirnya membentuk keseragaman yang murni dalam masyarakat. Sejarah yang sama berlaku di manamana tempat di seluruh dunia Islam semenjak dari perkembangan mazhab di peringkat awal lagi. Di Iraq contohnya untuk sekian lama penduduk Islamnya bermazhab dengan mazhab Abdullah bin Mas'ūd, di Hijaz dengan mazhab 'Abd Allah bin 'Umar, di Mekah Ațā’ bin Rabāḥ dan Mujāhid mendominasi fatwa-fatwa untuk sekian lama sehingga khalifah mengarahkan supaya segala fatwa

22 Wan Zulkifli Wan Hassan (2002), "Doktrin Sadd al Dhazara'i' dan pemakiannya dalam membendung ajaran sesat: satu kajian di JAKIM", Disertasi Sarjana, Jabatan Fiqh \& Usul, hh. 139-140. 
hendaklah diserahkan kepada dua orang tokoh ini. ${ }^{23}$ Jika amalan bermazhab ini dikatakan sebagai fanatik maka tidak ada tempat di dalam dunia Islam yang bebas dari fanatik mazhab. Ia adalah proses biasa dalam mana-mana tempat berkembangnya sesuatu mazhab. Bahkan boleh berlaku sesuatu tempat yang dikuasai oleh sesuatu mazhab akan bertukar penguasaannya oleh mazhab lain. Di Mesir umpamanya sebelum kedatangan Imam Syafi'i mazhab yang berkembang di situ ialah mazhab Malik, tetapi akhirnya mazhab Syafi'i mendominasi masyarakat Islam di situ hasil usaha murid-murid beliau yang memperkembangkan fiqhnya. ${ }^{24}$ Apa yang penting dipelajari ialah proses pertukaran mazhab itu berlaku dengan harmoni tanpa dipaksa ke atas masyarakat. Ia berlaku secara natural tanpa ada unsur paksaan atau tekanan. Sebarang tekanan atau paksaan akan menimbulkan reaksi yang tidak baik kepada masyarakat dan mungkin akan berlaku fanatik dalam mempertahankan mazhab masing-masing.

Walaubagaimanapun anjakan paradigma tetap berlaku dalam masyarakat Islam di Malaysia sekarang ini. Di peringkat pengajian tinggi, pengajian berorientasikan satu mazhab sahaja kelihatan sudah hilang. Sebagai gantinya pengajian fiqh secara perbandingan mazhab sudah diperkenalkan. Pendedahan kepada pelbagai pandangan dalam mazhab sudah boleh diterima secara umum sekurang-kurangnya di peringkat universiti dan ini menunjukkan unsur fanatik tidak wujud dalam amalan bermazhab di Malaysia. Walaupun secara rasminya bermazhab Syafi'i tetapi penerimaan kepada mazhab lain dalam konteks pengajian berkembang dengan baik dan lancar. Pendedahan ini sangat penting agar tidak timbul soal fanatik dalam bermazhab dan supaya pemikiran lebih maju ke hadapan. Dalam dunia yang global ini pertembungan budaya hasil perbezaan mazhab sangat mudah berlaku. Di sinilah pentingnya pengajian berorientaikan perbandingan mazhab supaya tidak timbul kekecohan dalam pertembungan tadi. Di masa yang sama kita masih mempertahankan pengajian bermazhab Syafi' $i$ di peringkat rendah dan menengah serta yang berbentuk umum sesuai dengan tahap pemikiran peringkat tersebut. Sekali lagi ditekankan ini bukan bermaksud fanatik mazhab tetapi demi untuk

23 Sai'‘̄id Ramaḍān al-Būți (1985) op.cit., h. 14.

24 Fawzì Fayḍ Allah (2001), Al-Madhāhib al-Fiqhiyyah. Damsyiq: Dār al-Qalam, h. 129. 
perkembangan pengajian pelajar agar pengetahuannya tentang fiqh dan manhaj mazhab terarah dengan baik dan sesuai dengan tahapnya.

Dalam fatwa pula perkembangan yang berlaku di zaman mutakhir ini menunjukkan pemakaian mazhab selain Syafi'i sudah banyak diadoptasikan. Walaupun dari segi peraturannya keutamaan diberikan kepada mazhab Syafi'i tetapi ternyata perkembangan semasa sekarang menuntut supaya kepentingan awam diutamakan. Dan ini sebenarnya masih selari dengan garis panduan fatwa yang diberikan di atas yang mana kepentingan awam diberi keutamaan. Garis panduan tersebut walaupun menampakkan unsur dominasi mazhab Syafi' $i$ tetapi kelonggaran tetap diberikan. Hasil daripada ini kita lihat banyak fatwa-fatwa seperti fatwa berkait istibdāl harta wakaf, zakat dan sebagainya yang melibatkan survival umat Islam telah tidak mengambil kira pandangan mazhab Syafi'i. Faktor budaya dan uruf setempat juga perlu diambil kira dalam berfatwa. Dalam masa yang sama usaha tajdid manhaj Syafi'i boleh digunapakai dalam menyelesai masalah-masalah baru dengan kerangka mazhab Syafi' $i$.

Proses yang sama berlaku dalam perbankan Islam yang mana demi kemudahan urusan orang ramai pandangan-pandangan dari mazhab lain turut diambil kira dan disesuaikan dengan keperluan tempatan $^{25}$. Ini semua berlaku dalam kerangka amalan bermazhab Syafi'i di negara ini yang mana penerimaannya telah terserap dengan harmoni dalam masyarakat Islam Malaysia. Oleh itu tidak wujud fanatik mazhab melihat kepada perkembangan yang berlaku.

25 Abdul Halim El-Muhammady, "Perubahan Hukum Muamalah Berdasarkan Teori Fiqh Malaysia: Satu Tinjauan" dalam Paizah Hj Ismail \& Ridzwan Ahmad, Fiqh Malaysia: Ke Arah Pembinaan Fiqh Tempatan Yang Terkini, Kuala Lumpur: Akademi Pengajian Islam, Universiti Malaya, hh. 198-199. 


\section{KESIMPULAN}

Berdasarkan perbincangan di atas ternyata bahawa mazhab Syafi'i adalah bertapak dengan kukuh dalam masyarakat Islam negara kita. Amalan bermazhab ini adalah satu keperluan dan tidak boleh diganggu gugat dengan aliran tidak bermazhab kerana banyak masalah yang akan timbul. Sejarah yang berlaku perlu diambil kira dalam kita membuat apa-apa tindakan yang berkait dengan mazhab di negara ini. Amalan yang berlaku adalah bukannya berasas kepada fanatik mazhab tetapi atas asas bertaqlid kepada imam mujtahid yang berkelayakan untuk berijtihad. Perkembangan-perkembangan yang berlaku dari segi peraturan, fatwa dan sebagainya adalah dalam kerangka tersebut demi menjaga perpaduan masyarakat dan mengambil kira sejarah yang membawa kepada kedudukan hari ini. Aliran tidak bermazhab yang diluar kerangka sebagaimana yang ada sekarang tidak boleh diberi ruang dalam negara ini kerana ia akan menghasilkan puluhan mazhab yang lain. Perselisihan pendapat adalah suatu yang tidak boleh dielak tetapi dalam kerangka bermazhab sekarang ini perselisihan boleh diminimakan dengan syarat tidak ada unsur fanatik. 